\title{
Analisis Video Comments to Image Comments Ratio Instagram Pada 5 Youtuber Indonesia dengan Subscribe Terbanyak \\ Bagus Made Rasa Adnyana
}

Email: aderasa19@gmail.com

\begin{abstract}
The development of information technology brings a change in society. The birth of social media makes people's behavior patterns experience a shift in culture, ethics and existing norms. Indonesia with a large population with various ethnic, racial and religious cultures has a lot of potential for social change. In this era of globalization, technology is increasingly advanced, it is undeniable that the presence of the internet is increasingly needed among people in daily life, be it socialization activities, education, business, and so on. For the community, especially teenagers, social media has become an addiction that makes users no day without opening social media. Whereas in its development period, in school, teenagers try to find their identity by hanging out with their peers. In this study, the researcher intends to explore the facts, symptoms and events of the influence of social media on adolescent behavior in the field as it is in the context of space and time as well as the natural environment of adolescents.
\end{abstract}

Keywords: Change; Social Media; Needs

\begin{abstract}
ABSTRAK
Perkembangan teknologi informasi membawa sebuah perubahan dalam masyarakat. Lahirnya media sosial menjadikan pola perilaku masyarakat mengalami pergeseran baik budaya, etikan dan norma yang ada. Indonesia dengan jumlah penduduk yang besar dengan berbagai kultur suku, ras dan agama yang beraneka ragam memiliki banyak sekali potensi perubahan sosial. Era globalisasi ini teknologi semakin maju, tidak dapat dipungkiri hadirnya internet semakin dibutuhkan di kalangan masyarakat dalam kehidupan sehari-hari, baik itu kegiatan sosialisasi, pendidikan, bisnis, dan sebagainya. Bagi masyarakat khususnya kalangan remaja, media sosial sudah menjadi candu yang membuat penggunanya tiada hari tanpa membuka media sosial. Padahal dalam masa perkembangannya, di sekolah remaja berusaha mencari identitasnya dengan bergaul bersama teman sebayanya. Dalam penelitian ini, peneliti bermaksud ingin mendalami suatu fakta, gejala dan peristiwa pengaruh media sosial terhadap perilaku remaja di lapangan sebagaimana adanya dalam konteks ruang dan waktu serta situasi lingkungan remaja secara alami.
\end{abstract}

Kata Kunci : Perubahan; Media Sosial; Kebutuhan

\section{PENDAHULUAN}

Media Sosial memiliki berbagai manfaat untuk manusia di era modern seperti saat ini, media sosial meghapus batasan - batasan manusia untuk bersosialisasi, batasan ruang maupun waktu, dengan media sosial manusia dimungkinkan untuk berkomunikasi satu sama lain dimanapun mereka bereda dan kapanpun, tidak peduli seberapa jauh jarak mereka dan mereka memiliki perasaan yang nyaman menggunakan media sosial yang dapat kita bilang media baru ini. (Structures, n.d.) 
Media sosial memiliki berbagai maanfaat yaitu ; sekedar untuk berkomunikasi dengan orang lain, untuk mencari tahu perkembangan sesuatu, untuk berbagi informasi maupun untuk mengikuti salah satu yang menjadi trend saat ini yaitu menggunakan media sosial sebagai bentuk eksistensi diri. Orang-orang yang hanya ingin menggunakan media sosial sebagai sarana menjaga silaturahmi biasanya akan memilih media sosial yang bersifat private saja seperti Line, Whatsapp, Path, Telegram, Blackberry Messenger atau yang lainnya. Meskipun masuk ke media yang terbuka seperti Facebook dan Twitter maka mereka hanya akan menjadi penonton dan pembaca yang baik dan melihat perkembangan terbaru yang ada di media sosial. Sedangkan bagi orang-orang yang ingin diakui eksistensinya oleh masyarakat luas melalui media sosial biasanya akan menggunakan media sosial yang bersifat terbuka seperti Instagram, Facebook, Line, atau Twitter. Karena disinilah tempat kita bisa secara bebas dan terbuka dalam berinteraksi. Sehingga banyaknya update status serta posting-an yang kita miliki adalah salah satu bentuk jika kita ingin dikenal secara luas. Kita dikenal sebagai apa dan siapa itu kita yang memutuskan, karena apa yang kita posting melalui media sosial akan menjadi gambaran diri kita bagaimana kita memposisikan diri dimata masyarakat luas. (Wylęgała, 2010)

Perkembangan teknologi informasi dan komunikasi telah mengubah cara interaksi individu dengan individu yang lain. Jika dilihat pada zaman dulu manusia atau seseorang yang ingin menceritakan perasaannya membutuhkan orang lain untuk mendengarkan ceritanya tersebut, keadaan tersebut bergeser dengan hadirnya buku tempat menuliskan curahan hati atau perasaan yang dikenal sebagai buku diary. Sekarang masyarakat berada pada arus perubahan yang sangat cepat akibat media sosial. (Moos, 1984)

\section{TINJAUAN PUSTAKA}

Instagram adalah sosial media berbasis gambar yang memberikan layanan berbagi foto atau video secara online. Instagram berasal dari pengertian dari keseluruhan fungsi aplikasi ini. Kata "insta" berasal dari kata "instan", seperti kamera polaroid yang pada masanya lebih dikenal dengan sebutan "foto instan". Instagram juga dapat menampilkan foto-foto secara instan, seperti polaroid di dalam tampilannya. Sedangkan untuk kata "gram" berasal dari kata "telegram" yang cara kerjanya untuk mengirimkan informasi kepada orang lain dengan cepat. Sama halnya dengan Instagram yang dapat mengunggah foto dengan menggunakan jaringan Internet, sehingga informasi yang ingin disampaikan dapat diterima dengan cepat. Oleh karena itulah Instagram merupakan lakuran dari kata instan dan telegram.

Melalui Instagram pengguna dapat mengunggah foto dan video pendek kemudian membagikannya kepada pengguna lain. Pada gambar yang diunggah, pengguna dapat menambahkan tag kepada orang tertentu dan penentuan lokasi. Pengguna juga dapat mengatur akun mereka sebagai "pribadi", sehingga mengharuskan mereka menyetujui setiap permintaan pengikut baru. Pengguna dapat menghubungkan akun Instagram mereka ke situs jejaring sosial lain, memungkinkan mereka untuk berbagi foto yang diunggah ke situs-situs tersebut.(Ii, 2018) 
Definisi media sosial yaitu suatu komunitas online untuk membagi informasi, ide, pendapat, pesan, dan video antar sesama penggunanya. Pengertian lain media sosial yaitu aplikasi atau website yang dapat digunakan penggunanya untuk menciptakan dan menyebarkan konten kepada jejaring sosial (misalnya teman, pengikut, dan sebagainya) yang dibangun untuk dirinya sendiri. Bentuk media sosial sangatlah bermacam-macam. Jejaring sosial adalah bentuk prototipe dari media sosial. Bentuk media sosial tidak hanya mencakup jejaring sosial, melainkan juga mencakup kategori media sharing, social news, dan kolaborasi konten lainnya.

Penggunaan istilah media sosial sering bertumpang tindih dengan jejaring sosial atau cakupan media sosial yang lain. Hal ini dikarenakan situs-situs media sosial tidak hanya terdiri dari satu jenis kategori seperti jejaring sosial saja, namun juga mencantumkan kategori lainnya. Contohnya yaitu situs seperti youtube, flickr, ataupun instagram, selain menjadi media sharing untuk video atau gambar, juga menjadi jejaring sosial dikarenakan memiliki fitur seperti profil, komentar, dan feedback.(Fallis, 2013)

\section{METODOLOGI PENELITIAN}

Dalam kasus penelitian ini, peneliti menggunakan metode eksploratif kuantitatif untuk mengetahui kredibilitas dari akun Instagram Pada 5 Youtuber Indonesia dengan Subscribe Terbanyak.

Dari penelitian ini bertujuan untuk mengetahui nilai kredibilitas dari performa akun Instagram 5 Youtuber Indonesia dengan Subscribe Terbanyak. Dalam perhitungan ini, terdapat beberapa langkah yang harus dilakukan dalam penelitian ini, sehingga mampu menemukan peringkat pertama akun Instagram Youtuber Indonesia dengan Subscribe Terbanyak yang memiliki performa terbaik. Langkah langkah yang dilakukan pada penelitian ini, yaitu:

\section{Melakukan Eksplorasi Pada Website Untuk Menentukan Objek Yang Akan Dianalisa.}

Eksplorasi ini dilakukan pada beberapa halaman website yang menyediakan informasi mengenai objek yang akan di teliti. Setelah eksplorasi tersebut selesai dilakukan, akan ditemukan nama nama youtuber Indonesia dengan Subscribe Terbanya yang akan dijadikan objek analisa. Langkah selanjutnya adalah mencari nama akun Instagram dari masing-masing youtuber Indonesia dengan Subscribe Terbanyak dan pastikan semua Youtuber Mempunyai akun pada aplikasi sosial media Instagram.

\section{Menghitung Nilai Rata-Rata Variable Dari 5 Youtuber Indonesia dengan Subscribe Terbanyak.}

Dalam langkah ini, peneliti melalukan perhitungan nilai variable video comments dan image comments. Variable merupakan segala sesuatu yang akan menjadi objek dalam sebuah penelitian (Astriani, 2014). Untuk menghitung nilai rata rata dari variable video comments dan variable image comments yaitu dengan cara mengambil minimal 10 
postingan kemudian di hitung sehingga menemukan nilai rata-rata dari masing masing variable.

\section{Menghitung Nilai Kredibilitas Rasio.}

Dalam menghitung nilai kredibilitas dari video comments to image comments ratio, peneliti menggunakan cara membagi nilai variable pertama dengan variable kedua. Jika video comment mempunyai nilai 400 dan image comments memiliki nilai 800 , maka cara menghitungnya yaitu $400: 800=0,5$. Dengan demikian dapat diperoleh hasil nilai dari video comments to image comments ratio adalah 0,5

\section{Menentukan Peringkat Pada Akun Instagram.}

Langkah yang terakhir dalam penelitian ini yaitu menentukan peringkat dari masing masing rasio yang ada. Saat menentukan peringkat perlu melihat karakteristik dari rasio yang di teliti. Jika karakteristik rasio bernilai tinggi, maka objek yang akan memiliki nilai tinggi akan mendapat angka 5 dan objek yang memperoleh nilai tinggi akan mendapatkan angka 1. Setelah mendapatkan hasil kredibilitas ratio maka dapat disimpulkan objek yang mana yang memperoleh peringkat 1 sampai dengan peringkat 5 .

\section{HASIL DAN PEMBAHASAN}

Akun Instagram dari 5 Youtuber Indonesia dengan Subscribe Terbanyak, diantaranya :

1. Atta Halilintar
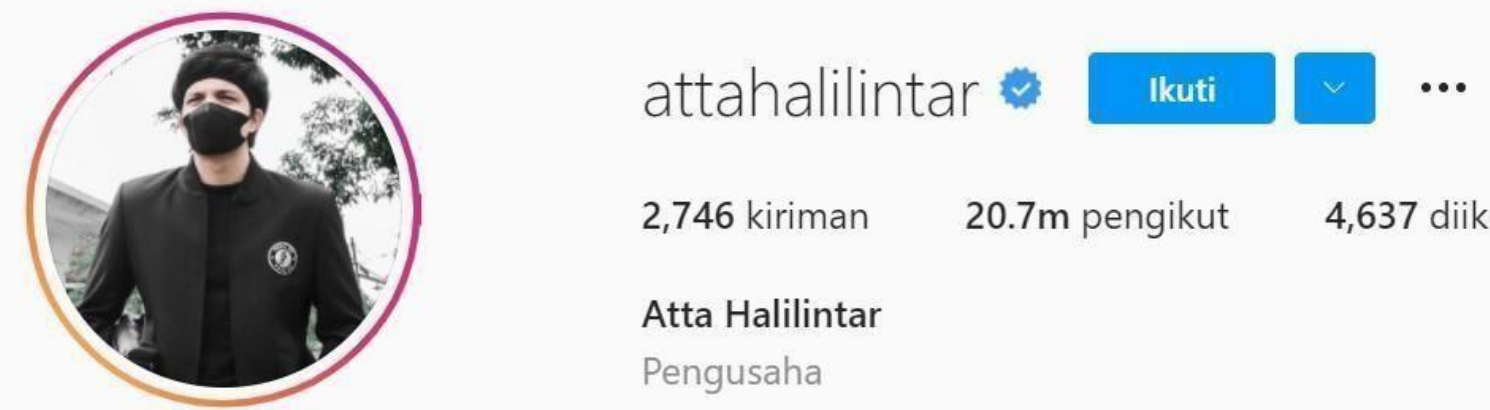

2,746 kiriman $\quad 20.7$ m pengikut $\quad 4,637$ diikuti

Atta Halilintar

Pengusaha

Gambar 1. Akun Instagram Atta Halilintar

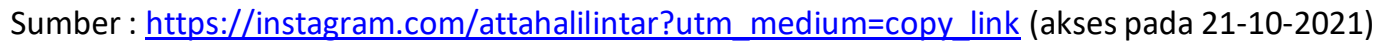

2. Ria Ricis
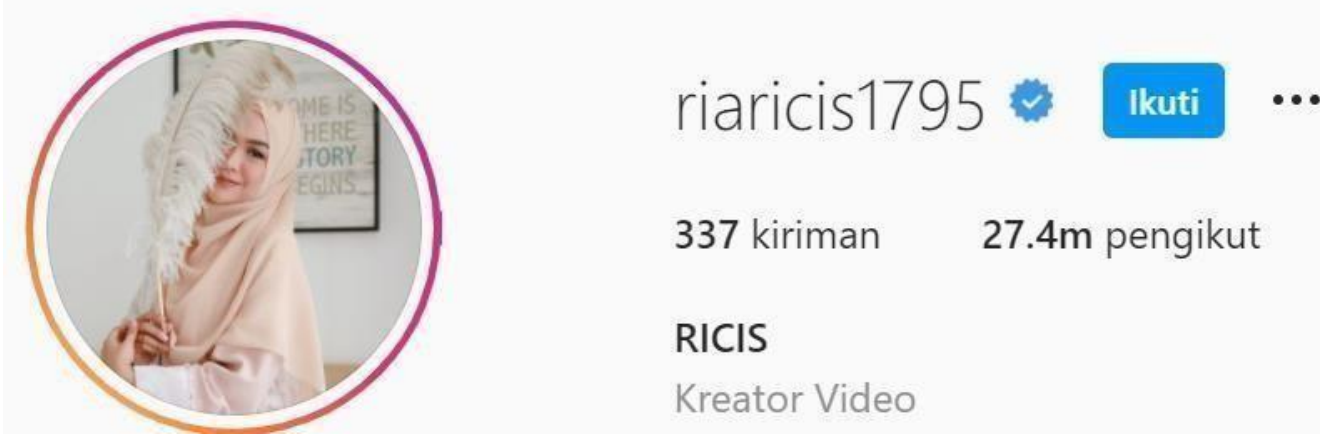

337 kiriman

$27.4 \mathrm{~m}$ pengikut

978 diikuti

RICIS

Kreator Video 
3. Jess No Limit
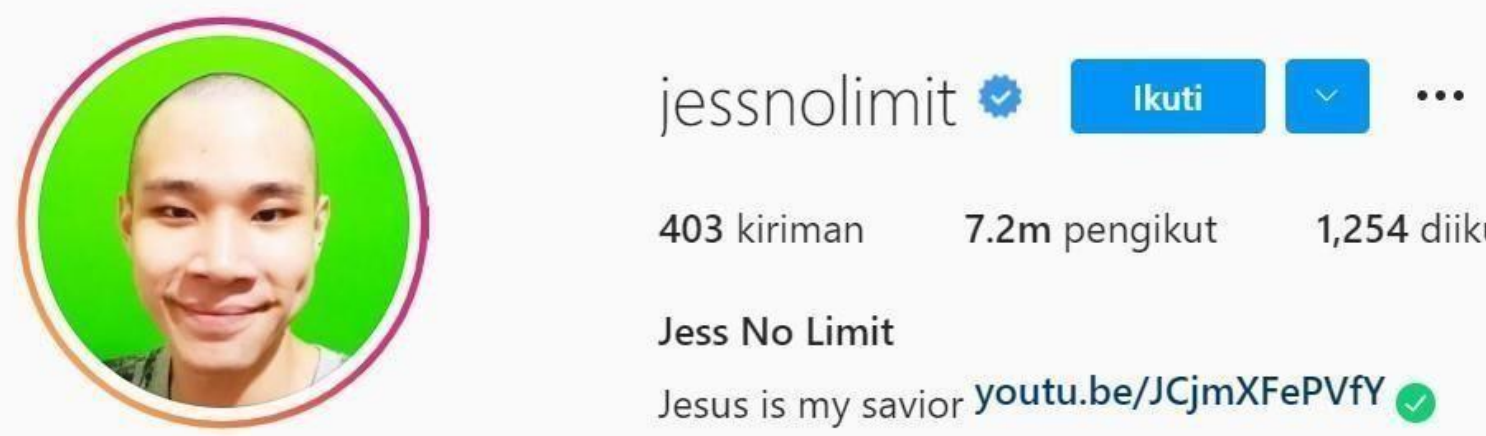

403 kiriman $\quad 7.2 \mathrm{~m}$ pengikut $\quad 1,254$ diikuti

Jess No Limit

Jesus is my savior youtu.be/JCjmXFePVfY

Gambar 3. Akun Instagram Jess No Limit

Sumber https://www.instagram.com/@jessnolimit?utm medium=copy link (akses pada 21-10-2021)

4. Rans Entertainment
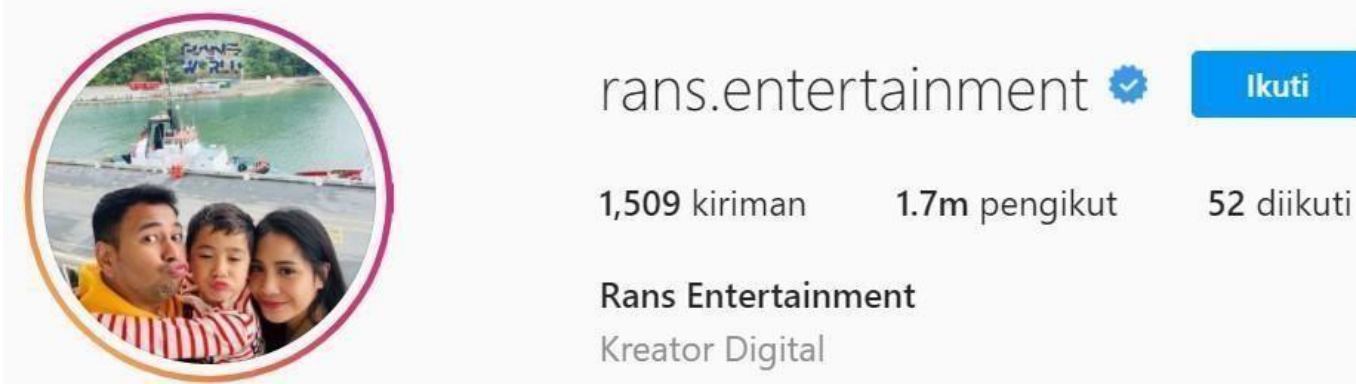

1,509 kiriman $\quad 1.7 \mathrm{~m}$ pengikut $\quad 52$ diikuti

Rans Entertainment

Kreator Digital

Gambar 4. Akun Instagram Rans Entertainment

Sumber: https://www.instagram.com/@rans.entertainment?utm medium=copy link (akses pada 21-10-2021)

5. Trans 7

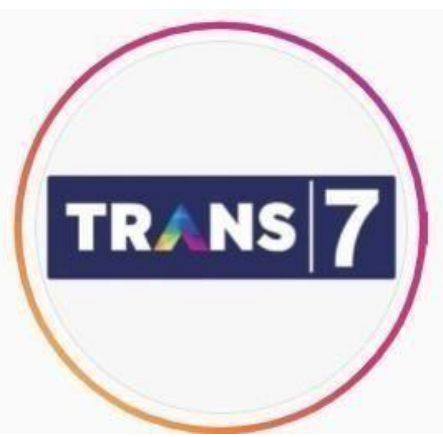

\section{officialtrans7}

15,551 kiriman

$2.6 \mathrm{~m}$ pengikut

TRANS7

Saluran TV

Gambar 5. Akun Instagram Trans 7

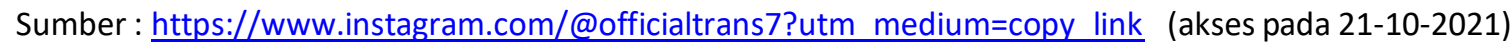


Dari kelima akun Instagram 5 Youtuber Indonesia dengan Subsribe Terbanyak, peneliti menemukan nilai dari masing - masing variabel yang ada untuk menghitung rasio Video Comments to Image Comments dari setiap akun. Pada akun Instagram terdapat 8 variabel, diantaranya yaitu : 1. Followers

2. Following

3. Video Likes

4. Video Comments

5. Video Views

6. Image Likes

7. Image Comments

8. Post

Dari kedelapan variabel tersebut peneliti hanya fokus untuk menemukan hasil dari 2 variabel, yaitu :

1. Video Comments

2. Image Comments

Dari kedua variabel tersebut kemudian dianalisa sehingga menemukan nilai rata-rata dari variabel video comments dan variabel Image Comments. Untuk menghitung nilai rata-rata dari variabel video comments dan variabel image comments yaitu dengan cara mengambil minimal 10 postingan kemudian di hitung sehingga menemukan nilai rata-rata dari masing-masing variabel. Berikut merupakan tabel nilai rata-rata dari masing-masing Youtuber Indonesia dengan Subscribe Terbanyak, yaitu :

Tabel 1. Analisa Nilai Rata-Rata Nilai Variabel Video Comments dan Image Comments Akun Instagram Atta Halilintar

\begin{tabular}{|r|r|r|}
\hline \multicolumn{2}{|c|}{ Atta Halilintar (@attahalilintar) } \\
\hline No & $\begin{array}{c}\text { Video } \\
\text { Comments }\end{array}$ & Image Comments \\
\hline 1 & 877 & 1.335 \\
\hline 2 & 1.221 & 2.333 \\
\hline 3 & 3.545 & 1.051 \\
\hline 4 & 4.340 & 1.745 \\
\hline 5 & 1.040 & 1.621 \\
\hline 6 & 3.333 & 1.363 \\
\hline 7 & 1.035 & 1.290 \\
\hline 8 & 1.047 & 1.600 \\
\hline 9 & 2.595 & 5.834 \\
\hline 10 & 1.059 & 96.562 \\
\hline Total & 2.009 & 11.473 \\
\hline
\end{tabular}

Sumber : Pengolah Data Excel

Tabel 2. Analisa Nilai Rata-Rata Nilai Variabel Video Comments dan Image Comments Akun Instagram Ria Ricis 


\begin{tabular}{|r|r|r|}
\hline \multicolumn{3}{|c|}{ Ria Ricis (@riaricis1795) } \\
\hline No & $\begin{array}{c}\text { Video } \\
\text { Comments }\end{array}$ & Image Comments \\
\hline 1 & 2.677 & 8.975 \\
\hline 2 & 491 & 2.665 \\
\hline 3 & 6.376 & 2.736 \\
\hline 4 & 1.539 & 3.943 \\
\hline 5 & 2.547 & 2.924 \\
\hline 6 & 1.068 & 5.539 \\
\hline 7 & 22.342 & 8.250 \\
\hline 8 & 3.508 & 8.069 \\
\hline 9 & 2.323 & 6.367 \\
\hline 10 & 3.992 & 4.319 \\
\hline Total & 4.686 & 5.379 \\
\hline
\end{tabular}

Sumber : Pengolah Data Excel

Tabel 3. Analisa Nilai Rata-Rata Nilai Variabel Video Comments dan Image Comments Akun Instagram Jess No Limit

\begin{tabular}{|r|r|r|}
\hline \multicolumn{2}{|c|}{ Jess No Limit (@jessnolimit) } \\
\hline No & $\begin{array}{c}\text { Video } \\
\text { Comments }\end{array}$ & Image Comments \\
\hline 1 & 273 & 1.506 \\
\hline 2 & 538 & 1.940 \\
\hline 3 & 2.233 & 2.777 \\
\hline 4 & 4.000 & 6.390 \\
\hline 5 & 463 & 3.254 \\
\hline 6 & 4.800 & 569 \\
\hline 7 & 7.608 & 459 \\
\hline 8 & 11.335 & 408 \\
\hline 9 & 401 & 2.500 \\
\hline 10 & 5.380 & 1.987 \\
\hline Total & 3.703 & 2.179 \\
\hline
\end{tabular}

Sumber : Pengolah Data Excel

Tabel 4. Analisa Nilai Rata-Rata Nilai Variabel Video Comments dan Image Comments Akun Instagram Rans Entertainment 


\begin{tabular}{|r|r|r|}
\hline No & \multicolumn{2}{|c|}{$\begin{array}{l}\text { Video } \\
\text { Comments }\end{array}$} \\
\hline 1 & 59 & Image Comments \\
\hline 2 & 47 & 36 \\
\hline 3 & 97 & 1.385 \\
\hline 4 & 107 & 420 \\
\hline 5 & 499 & 40 \\
\hline 6 & 157 & 302 \\
\hline 7 & 289 & 67 \\
\hline 8 & 101 & 552 \\
\hline 9 & 2.062 & 1.226 \\
\hline 10 & 75 & 25 \\
\hline Total & 349 & 408 \\
\hline
\end{tabular}

Sumber : Pengolah Data Excel

Tabel 5. Analisa Nilai Rata-Rata Nilai Variabel Video Comments dan Image Comments Akun Instagram Trans 7

\begin{tabular}{|r|r|r|}
\hline \multicolumn{3}{|c|}{ Trans7 (@officialtrans7) } \\
\hline No & $\begin{array}{c}\text { Video } \\
\text { Comments }\end{array}$ & Image Comments \\
\hline 1 & 1 & 2 \\
\hline 2 & 1 & 5 \\
\hline 3 & 17 & 1.595 \\
\hline 4 & 69 & 4 \\
\hline 5 & 2 & 33 \\
\hline 6 & 26 & 128 \\
\hline 7 & 2 & 20 \\
\hline 8 & 38 & 4.990 \\
\hline 9 & 145 & 7 \\
\hline 10 & 2 & 0 \\
\hline Total & 30 & 678 \\
\hline
\end{tabular}

Sumber Pengolah Data Excel

Setelah menghitung nilai rata rata tersebut, maka akan menemukan hasil akhir nilai rata-rata dari variabel video comments dan variabel image comments ratio

Tabel 6. Nilai Variabel Pada Akun Instagram 5 Youtuber Indonesia dengan Subscribe Terbanyak

Nilai dari masing-masing Variabel

\begin{tabular}{|l|l|l|}
\hline Variabel & Video Commentes & Image Comments \\
\hline
\end{tabular}




\begin{tabular}{|l|r|r|}
\hline Atta Halilintar & 2009,2 & 11473,4 \\
\hline Riarcis & 4686,3 & 5378,7 \\
\hline Jess No Limit & 3703,1 & 2179 \\
\hline Rans & 349,3 & 408,1 \\
\hline Trans7 & 30,3 & 678,4 \\
\hline
\end{tabular}

Sumber : Pengolah Data Excel

Pada akun Instagram terdapat 8 rasio yang relevan digunakan untuk mengukur kredibilitas pada masing-masing akun. Namun pada penelitian kali ini hanya berfokus untuk menghitung Video Comments to Image Comments Ratio. Untuk menghitung kredibilitas dari masing-masing akun Instagram setiap Youtuber, peneliti menghitung dengan cara : variabel 1 akan dibagi dengan variabel 2, sehingga ditemukan hasil analisisa dari rasio tersebut.

Tabel 7. Hasil Perhitungan Rasio Akun Instagram

Ratio Video Comments to Image Comments
\begin{tabular}{|l|r|r|r|}
\hline Variabel & Video Commentes & Image Comments & Ratio \\
\hline Atta Halilintar & 2.009 & 11.473 & 0,175 \\
\hline Riarcis & 4.686 & 5.379 & 0,871 \\
\hline Jess No Limit & 3.703 & 2.179 & 1,699 \\
\hline Rans & 349 & 408 & 0,856 \\
\hline Trans7 & 30 & 678 & 0,045 \\
\hline
\end{tabular}

Sumber : Pengolah Data Excel

Video Comments to Image Comments Ratio memiliki karakteristik yang tinggi, artinya semakin tinggi nilai yang dihasilkan maka semakin baik kredibilitas dari performa akun tersebut. Untuk memberikan peringkat pada masing-masing Youtuber, peneliti memberikan angka 5 kepada vendor yang mendapatkan nilai tertinggi dan angka 1 untuk vendor yang mendapatkan nilai terendah. Berikut merupakan tabel urutan nilai yang dihasilkan oleh masing - masing Youtuber.

Tabel 8. Nilai Rasio Akun Instagram 5 Youtuber Indonesia dengan Subscribe Terbanyak

\begin{tabular}{|l|r|l|}
\hline Variabel & Ratio & Nilai \\
\hline Atta Halilintar & 0,175 & 2 \\
\hline Riarcis & 0,871 & 4 \\
\hline Jess No Limit & 1,699 & 5 \\
\hline Rans & 0,856 & 3 \\
\hline Trans7 & 0,045 & 1 \\
\hline
\end{tabular}


Setelah menentukan nilai, selanjutnya penentukan peringkat

Tabel 9. Nilai Rasio Akun Instagram 5 Youtuber Indonesia dengan Subscribe Terbanyak

\begin{tabular}{|l|r|r|}
\hline Variabel & Nilai & Peringkat \\
\hline Atta Halilintar & 2 & 4 \\
\hline Riarcis & 4 & 2 \\
\hline Jess No Limit & 5 & 1 \\
\hline Rans & 3 & 3 \\
\hline Trans7 & 1 & 5 \\
\hline
\end{tabular}

Sumber Pengolah Data Excel

Dari Tabel Nilai Rasio Akun Instagram 5 Youtuber Indonesia dengan Subscribe Terbanyak dapat simpulkan bahwa Jess No Limit mendapatkan nilai tertinggi untuk rasio Video Comments to Image Comments. Sedangkan akun Instagram Trans 7 mendapatkan nilai terendah untuk rasio ini. Jadi, pada penelitian ini Jess No Limit memiliki kredibilitas performa yang lebih baik dibandingkan dengan Youtuber lainnya.

\section{Kesimpulan}

Tujuan dari penelitian ini adalah mengetahui kredibilitas performa dari akun Instagram 5 Youtuber Indonesia dengan Subscribe Terbanyak menggunakan Video Comments to Image Comments Ratio. 5 Youtuber Indonesia dengan Subscribe Terbanyak tersebut diantaranya : Jess No Limit, Ria Ricis, Rans, Atta Halilintar, Trans 7. Dari kelima Youtuber tersebut dapat disimpulkan bahwa :

1. Peringkat pertama diraih oleh Youtuber Jess No Limit dengan nilai tertinggi yaitu 1,699

2. Peringkat kedua diraih oleh Youtuber Ria Ricis dengan nilai yaitu 0,871

3. Peringkat ketiga diraih oleh Youtuber RANS dengan nilai yaitu 0,856

4. Peringkat keempat diraih oleh Youtuber Atta Halilintar dengan nilai yaitu 0,175

5. Peringkat kelima diraih oleh Youtuber Trans 7 dengan nilai yaitu 0,045 


\section{DAFTAR PUSTAKA}

Fallis, A. . (2013). Pengertian Instagram. Journal of Chemical Information and Modeling, 53(9), 1689-1699.

Ii, B. A. B. (2018). Hubungan Intensitas Penggunaan Media Sosial Dengan Gejala Depresi Mahasiswa Kedokteran (Studi Pada Mahasiswa Kedokteran Tingkat Akhir Yang Menggunakan Kurikulum Modul Terintegrasi). Diponegoro Medical Journal (Jurnal Kedokteran Diponegoro), 7(2), 919934.

Moos. (1984). No Title Детская неврология. Ekp, 13(3), 576.

Structures, M. B. (n.d.). No 主観的健康感を中心とした在宅高齢者における 健康関連指標に関 する共分散構造分析 Title. 1-9.

Wylęgała, L. (2010). No 主観的健康感を中心とした在宅高需者における 健康関連指標に関す る共分散構造分析 Title. 2005, 1-12. 